\title{
Práticas educativas e o ensino de arte na educação profissional e tecnológica
}

\author{
Educational practices and art teaching in professional and technological \\ education
}

\section{Prácticas educativas y enseñanza del arte en la educación professional y tecnológica}

Bortolin, Luana Cassol' (Farroupilha, RS, Brasil) ORCID ID: https://orcid.org/0000-0003-1129-4625

Brancher, Vantoir Roberto² (Santa Maria, RS, Brasil) ORCID ID: https://orcid.org/0000-0003-2829-7320 Paniz, Catiane Mazocco ${ }^{3}$ (Cidade, Estado e País) ORCID ID: https://orcid.org/0000-0003-2999-796X

\begin{abstract}
Resumo
Este artigo tem como objetivo compreender as práticas educativas dos professores de arte na educação profissional e discutir como a arte tem colaborado para integração curricular. Deste modo, por meio de uma metodologia qualitativa foram realizadas entrevistas semi-estruturadas com cinco professores de arte atuantes de um Instituto Federal de Educação, Ciência e Tecnologia. Para a análise das narrativas foi necessária análise de conteúdo Bardin (2006). Nos apoiamos em interlocutores como Barbosa (2010), Araújo e Frigotto (2015), Araújo e Rodrigues (2010), Zabala (1998) os quais, auxiliaram na interpretação dos dados. Foi possível observar que a arte tem um papel fundamental no ensino integrado por articular a estética, a reflexão, a crítica e a política, contribuindo, deste modo, para a formação e autonomia do sujeito.
\end{abstract}

Palavras-chave: Práticas educativas. Ensino de arte. Educação profissional

\begin{abstract}
This article aims to understand the educational practices of art teachers in professional education and discuss how art has contributed to curricular integration. Thus, through a qualitative methodology, semistructured interviews were carried out with five art teachers working at a Federal Institute of Science and Technology. For the analysis of the narratives, content analysis was necessary Bardin (2006) and authors such as Barbosa (2010), Araújo and Frigotto (2015), Araújo and Rodrigues (2010), Zabala (1998) helped in the interpretation of the data. Therefore, it was observed that art has a fundamental role in integrated education by articulating aesthetics, reflection, criticism and politics, thus contributing to the formation and autonomy of the subject.
\end{abstract}

Keyword: Educational Practices. Art Teaching. Professional education

\section{Resumen}

Este artículo tiene como objetivo comprender las prácticas educativas de los profesores de arte en la educación profesional y discutir cómo el arte ha contribuido a la integración curricular. Por lo tanto, a través de una metodología cualitativa, se realizaron entrevistas semiestructuradas con cinco maestros de arte que trabajan en un Instituto Federal de Educación, Ciencia y Tecnología. Para el análisis de las

\footnotetext{
${ }^{1}$ Coordenadora de formação continuada de Arte da Prefeitura Municipal de Uruguaiana e Professora de arte da Secretaria Municipal de Educação Uruguaiana. Iuana.cassol@hotmail.com

2 Professor efetivo do Instituto Federal de Educação Ciência e Tecnologia Farroupilha, atuando em cursos de Licenciatura e Pós-Graduação em Educação Profissional - ProfEPT. vantoir.brancher@iffarroupilha.edu.br

3 É professora de ensino básico, técnico e tecnológico do Instituto Federal Farroupilha- campus São Vicente do Sul. Professora do Programa de Pós-Graduação em Educação Profissional e Tecnológica (PROFEPT). catiane.paniz@iffarroupilha.edu.br
} 
narrativas, fue necesario el análisis de contenido de Bardin (2006). Confiamos en interlocutores como Barbosa (2010), Araújo y Frigotto (2015), Araújo y Rodrigues (2010), Zabala (1998) que ayudaron en la interpretación de los datos. Se pudo observar que el arte juega un papel fundamental en la enseñanza integrada, ya que articula la estética, la reflexión, la crítica y la política, contribuyendo así a la formación y la autonomía de la asignatura.

Palabras clave: Prácticas educativas. Enseñanza de arte. Educación profesional

\title{
1 Introdução
}

O ensino de arte, rememorando-o através de Barbosa (2010), demonstra que em relação à educação profissional, configurou-se a visão da arte como preparação para o trabalho, no fim do século XIX, ancorada pelas ideias liberais de Rui Barbosa, André Rebouças e Abílio César Borges. Este espectro estava ligado ao antiescravagismo e à aparente preocupação de ocupar os escravos recém-libertos para o mercado de trabalho, ou seja, para que conseguissem empregos.

Neste contexto, o ensino de arte estava voltado para aprendizagem do desenho geométrico, do decorativismo e à ampliação de figuras para serem trabalhadas na construção civil. Ou seja, o estudo de arte servia para aplicar métodos e técnicas no trabalho.

Relacionando o ensino de arte com a gênese da educação profissional no Brasil, segundo Moura (2008) essa foi destinada ao preparo, para o mercado de trabalho, das classes menos favorecidas. Com a criação dos Institutos Federais de Ciência e Tecnologia a partir da Lei de 11.892/2008 (BRASIL, 2008) a educação profissional está voltada a proposta de uma formação integral do ser humano articulada ao mundo do trabalho e ao desenvolvimento pleno do estudante:

\begin{abstract}
Não apenas uma forma de oferta da educação profissional de nível médio, o ensino integrado é uma proposição pedagógica que se compromete com a utopia de uma formação inteira, que não se satisfaz com a socialização de fragmentos da cultura sistematizada e que compreende como direito de todos o acesso a um processo formativo, inclusive escolar, que promova o desenvolvimento de suas amplas faculdades físicas e intelectuais. (ARAÚJO; FRIGOTTO, 2015, p. 62).
\end{abstract}

Dialogando com Araújo e Frigotto (2015) o Ensino Médio Integrado na educação profissional, hoje, corresponde com a não formação de mão-de-obra para o mercado de trabalho, mas uma formação integral que seja coerente com um processo formativo para a vida. Deste modo, é importante compreender como estão 
sendo articuladas as práticas educativas dos professores de arte neste novo contexto da educação profissional tecnológica.

\section{Práticas Educativas na Educação Profissional e Tecnológica}

Relacionando os pressupostos teóricos entre trabalho e educação, Saviani (2007) destaca ambos como algo inerente ao homem, e sua consequente separação como algo advindo da própria separação de classes pela sociedade.

Pressupõe-se, portanto, uma definição de homem que indique em que ele consiste, isto é, sua característica essencial a partir da qual se possa explicar o trabalho e educação como atributos do homem. E, nesse caso, fica aberta a possibilidade de que trabalho e educação sejam considerados atributos essenciais do homem, ou acidentais. (p. 153).

Dialogando com Saviani (2007) a existência humana não é garantida totalmente pela natureza, pois precisa ser produzida pelos próprios homens, sendo ela também um produto do trabalho. Logo, o homem forma-se homem, necessita aprender a produzir sua própria existência e sua formação é também um processo educativo. A origem da educação e do trabalho coincide com a gênese da humanidade. Através do trabalho o homem produziu-se e educou a si e as outras gerações, ainda Coelho e Sousa (2019, p.13) refletem que "(...) o homem apropria-se do conhecimento já produzido pela humanidade para reformulá-lo e aplicá-lo no processo de mediação de sua existência".

Para Marx (2004) o trabalho em sua perspectiva ontológica coincide com a produção pela realização, a produção como algo criativo e inerente ao homem. Mas o trabalho tornou uma perspectiva histórica quando foi pensado para o mercado e para o lucro como fornecimento de mão-de-obra para o capitalismo. Neste caso, trabalho é cronometrado, é fração de dinheiro e, por vezes, perde-se a dimensão ontológica e criativa do labor.

Esta perspectiva histórica do trabalho caracteriza também a divisão da sociedade em classes que rompeu com a comunidade entre trabalho e educação. $A$ partir disso, constitui-se uma forma específica e institucionalizada de ensino que dissolveu o trabalho como algo "manual e menor" e a educação como "intelectual e maior". 
Neste ínterim, a educação profissional, principalmente, foi vestida pelas características do modo de produção capitalista. Logo, as instituições de ensino profissionalizantes, historicamente, no Brasil tiveram propriedades de ensino tecnicista para formar os estudantes e ocupá-los diretamente no mercado de trabalho.

Araújo e Rodrigues (2010) demarcam temporalmente que o período de 1930 a 1940 foi caracterizado pela institucionalização da educação profissional no Brasil com o sistema "S" de ensino e as legislações orgânicas. As ideologias de uma industrialização nascente no país demandavam por formação de trabalhadores aptos e a educação profissional foi a chave para este fim. Estes autores identificam práticas educativas em educação profissional encontradas no país a partir desta época: as Séries Metódicas de Ofício e, mais tarde, a Pedagogia das Competências.

As Séries Metódicas de Ofício tinham como objetivos a assimilação da realidade com métodos de ensino programados que priorizavam o disciplinamento do aluno por meio do controle do processo de aprendizagem. Os conteúdos eram sequenciados por temas fragmentados. Logo, a institucionalização da educação profissional no Brasil foi caracterizada historicamente por uma pedagogia tecnicista. (ARAÚJO; RODRIGUES, 2010)

A partir de 1980 a Pedagogia das Competências foi a prática formativa em educação profissional mais relevante. Esta previa uma Organização Curricular Modular com objetivos formativos comprometidos com a máxima eficiência para atender posteriormente os setores produtivos. As práticas avaliativas serviam para medir rigorosamente as competências dos alunos. De acordo com Araújo e Rodrigues (2010) a base e influência teórica para a didática da pedagogia das competências é o racionalismo, o individualismo e o neopragmatismo. Segundo Antunes e Alves (2004) com o modo de produção flexível chamado Toyotista houve uma redução do proletariado estável como anteriormente, e assumiu-se uma precarização intensa do trabalho com os modos de terceirização. Houve nos setores produtivos a modalidade de flexibilização, a desconcentração do espaço físico e a introdução da informática.

Deste modo, a Pedagogia das Competências estava interligada a esta nova forma de produção flexível. Com características de ensino como o racionalismo que favorece a sequência lógica nos processos de trabalho, gerando controle desta 
sequência ocasionará eficiência no trabalho. Assim como a referência individualista tem a necessidade do desenvolvimento das competências individuais de um aluno e enfraquece 0 senso de envolvimento coletivo entre os trabalhadores a base neopragmatista da pedagogia das competências visa a adaptabilidade, o utilitarismo e busca produzir aprendizagens úteis e aplicáveis ao mercado.

A precarização do trabalho de acordo com Antunes e Alves (2004) demonstra a necessidade de trabalhadores adaptáveis às ingerências da produção. Logo, a educação profissional esteve voltada a este objetivo naquele momento.

Podemos entender que historicamente a educação profissional no Brasil esteve adepta às exigências dos setores industriais e capitalistas. Com o ensino tecnicista e pragmatista formavam estudantes com a perspectiva de abastecerem o mercado de trabalho sem pensar na formação inteira e integral do sujeito.

Araújo e Frigotto (2015) falam que o ensino integrado não visa mais uma educação utilitária como anteriormente e sim:

(...) exige uma crítica às perspectivas reducionistas de ensino que se comprometem em desenvolver algumas atividades humanas em detrimento de outras, (...) o desenvolvimento de capacidade cognitiva básica e instrumental em detrimento do desenvolvimento de sua força criativa e de sua autonomia intelectual e política. (p.63).

Essa superação entre trabalho e educação advinda historicamente, e o desenvolvimento da autonomia intelectual e política é o que visam hoje os Institutos Federais de Ciência e Tecnologia. Pois em uma educação voltada para a formação plena e inteira, podemos abranger o trabalho como princípio educativo, como produção criativa e genuinamente humana.

Deste modo, é preciso compreender como estão os professores de arte articulando-se com suas práticas educativas para a integração curricular e como a arte vem a contribuir para a formação humana integral e plena. Sendo assim, o objetivo deste trabalho foi discutir sobre as práticas educativas do ensino de arte no Ensino Médio Integrado, bem como verificar a contribuição deste componente curricular na integração curricular.

\section{Metodologia}


Este estudo caracteriza-se por investigar sobre as práticas educativas de professores de arte da educação básica profissional e tecnológica. Dessa forma, esta investigação organizou-se através de uma pesquisa qualitativa, que segundo Triviñus (1987) significa:

[...] por um lado, que ela compreende atividades de investigação que podem ser denominadas específicas. E, por outro, que todas elas podem ser caracterizadas por traços comuns. Esta é uma ideia fundamental que pode ajudar a ter uma visão mais clara do que pode chegar a realizar um pesquisador que tem por objetivo atingir uma interpretação da realidade do ângulo qualitativo. (p.121)

Deste modo, foi organizada uma entrevista semiestruturada que foi implementada. com cinco docentes de arte de um Instituto Federal de Ciência e Tecnologia a fim de termos maior compreensão e aproximação sobre o ensino de arte no currículo integrado. A entrevista semiestruturada pressupõe:

[...] parte de certos questionamentos básicos, apoiados em teorias e hipóteses, que interessam à pesquisa, e que, em seguida, oferecem amplo campo de interrogativas, fruto de novas hipóteses que vão surgindo à medida que se recebem as respostas do informante. Desta maneira, o informante, seguindo espontaneamente a linha de seu pensamento e de suas experiências dentro do foco principal colocado pelo investigador, começa a participar na elaboração do conteúdo da pesquisa. (TRIVIÑUS 1987, p.146)

Nas pesquisas qualitativas, as entrevistas semiestruturadas auxiliam na aproximação do pesquisador com os colaboradores, pois é um instrumento por meio do qual o lugar de fala, as gesticulações dos sujeitos também se evidenciam, materializando sua importância bem com uma possível apreensão da realidade investigada. Em relação às realizações das entrevistas, estas ocorreram, previamente, com hora e data marcadas com os colaboradores. Foi utilizado gravador de voz e o roteiro de perguntas já estabelecidas.

Seguindo, o planejamento estabelecido no intuito de respeitar os pressupostos teóricos e a ética na pesquisa foi apresentada a Carta de Apresentação, a assinatura do Termo de Consentimento Livre e Esclarecido e entregue o Termo de Confidencialidade. Caso a leitura e a assinatura de tais termos não ocorressem isso seria um critério de exclusão para a não realização da entrevista.

Através das narrativas dos entrevistados se fez a categorização a partir da análise de conteúdo de Bardin (2016) que consiste na: pré-análise, exploração do 
material, tratamento dos dados e interpretação. A primeira fase denominada préanálise é o período de organizar as ideias iniciantes conforme os objetivos da pesquisa. Na segunda etapa com a exploração do material deve-se fazer recortes e categorizações conceituais das consecutivas repetições de palavras e enunciações para depois seguir com a interpretação dos dados. A análise e interpretação teve em vista a compreensão das práticas educativas dos professores de arte entrevistados. Esta pesquisa pretende trazer uma repercussão para discutir o ensino de arte no âmbito da educação profissional e tecnológica de que modo pode ser ampliada a percepção sobre a mesma.

4 Análise e Discussão dos dados: Considerações sobre o Ensino de arte na Educação Profissional e Tecnológica

A amostra contou com cinco participantes que lecionam arte no Ensino Médio Integrado. Para fins de confidencialidade dos colaboradores foram elencadas letras A, B, C, D, E para codificar seus nomes. No Quadro 1 está especificada a formação e a titulação dos participantes.

Quadro 1. Perfil dos Participantes da Pesquisa

\begin{tabular}{|l|c|l|}
\hline \multicolumn{1}{|c|}{ Colaboradores } & $\begin{array}{c}\text { Tempo de docência } \\
\text { na EBPT }\end{array}$ & \multicolumn{1}{|c|}{ Formação/Titulação } \\
\hline Professor A & 2 anos & $\begin{array}{l}\text { Licenciatura em Artes Visuais } \\
\text { Mestre e Doutor }\end{array}$ \\
\hline Professor B & 9 anos & $\begin{array}{l}\text { Licenciatura em Artes Visuais } \\
\text { Especialista }\end{array}$ \\
\hline Professor C & 5 anos & $\begin{array}{l}\text { Licenciatura em Música } \\
\text { Mestre }\end{array}$ \\
\hline Professor D & 6 anos & $\begin{array}{l}\text { Licenciatura em Artes Visuais } \\
\text { Mestre }\end{array}$ \\
\hline Professor E & 3 anos & $\begin{array}{l}\text { Licenciatura em Música } \\
\text { Mestre }\end{array}$ \\
\hline
\end{tabular}

Fonte: autores, 2020. 
Em relação aos colaboradores todos possuem formação na área de arte, três são Licenciados em Artes Visuais e dois são Licenciados em Música. Mas todos lecionam arte nas suas unidades de ensino.

Sabendo do histórico da educação profissional, tivemos no Brasil, práticas educativas voltadas para o tecnicismo e o disciplinamento do estudante para abastecer o mercado de trabalho (ARAÚJO; RODRIGUES, 2010). Hoje, no contexto do currículo integrado, a perspectiva de ensino na educação profissional é outra, pois os Institutos Federais acreditam na formação humana integral e plena, na consciência crítica para a atuação no mundo do trabalho.

A partir desta breve contextualização, sabemos que na realidade a integração curricular não é tarefa instantânea. Ao contrário, exige tempo e dedicação coletiva dos docentes, e mesmo assim, há muito ainda o que pensar em como os componentes curriculares podem dialogar em prol da concepção de ser humano e sociedade que visam formar. Nesse sentido, temos o objetivo também de compreender como os professores de arte estão atuando no ensino e como estão contribuindo para a integração curricular.

Para Marques (2000) educar, por muito tempo, teve como objetivo inserir o educando na ordem do ser e do mundo. O ensino, neste sentido, foi sinônimo de transmitir e repetir verdades imutáveis e aprender o que significava assimilar passivamente estas verdades através da memorização. Este mesmo autor reitera que "O conhecimento da natureza mesma das coisas se distingue do saber vulgar, do senso comum." (p.116) A educação nesta definição foi denominada pelo paradigma essencialista. Este paradigma educacional aborda o aluno como uma "tábula rasa", não percebe o aluno como um sujeito, com sua biografia e com os aprendizados que compartilha da sua própria cultura.

Hoje, segundo Marques (2000) o conhecimento faz sentido na partilha, ele é construído e reconstruído por diálogo e prática social. O paradigma da interlocução de saberes entende a ação educativa de modo dialógico, onde os alunos participam ativamente do processo de aprendizagem e da construção do conhecimento. Tanto o estudante quanto o professor fazem parte desta dimensão dialógica onde "o já 
existente e o novo se entrelaçam nos significados e conteúdos da tradição cultural." (p.120)

Deste modo, relacionamos as práticas educativas dos professores de arte colaboradores com o paradigma da interlocução de saberes, pois segundo seus relatos, eles tendem a aproximar os conteúdos de arte com a vida dos estudantes.

Eu sempre explico porque estudar arte, a importância da arte para a formação profissional e para a vida deles. A importância de se entender a nossa cultura e o papel da arte na vida da gente. Não temos necessariamente que ser artistas, mas que estudamos a arte para a nossa vida. (Professor E)

Este relato do Professor E demonstra a relação que estabelece entre os conhecimentos de arte e a vida, bem como o reconhecimento da cultura dos alunos e o papel da arte nessa realidade. Do mesmo modo a fala seguinte demonstra a necessidade em articular os conteúdos acadêmicos com a vida dos estudantes:

Gosto de trabalhar com projetos que articulem diferentes campos do conhecimento e diferentes culturas. Projetos de trabalho que articulem não só os conhecimentos acadêmicos, mas a vida dos nossos estudantes. (Professor C)

Para dialogar sobre os Projetos de Trabalho, Hernández (1998) traz a necessidade que se estabeleça a integração do currículo por projetos, pois assim se desfaz a fragmentação por disciplinas e favorece mudanças na realidade educativa. A pesquisa, no ensino, favorece o compartilhamento do conhecimento com as experiências dos estudantes.

Da mesma forma o Professor A trabalha com a história da arte e pesquisas teóricas, mas releva a importância da formação dos sujeitos no processo de aprendizagem.

A gente trabalha com a história da arte, fizemos pesquisas teóricas, mas vai da formação deles como pessoa, eu acho muito importante trazer isso. (Professor A)

Essa interlocução dos saberes demonstra a aproximação do que se ensina com quem aprende. Quando os professores tecem relações entre os conteúdos de arte e o contexto vivencial e cultural dos alunos significa que valorizam a biografia e 
os aspectos formativos vividos fora do ambiente educativo. Do mesmo modo seguem os relatos:

Eu pondero sempre assim e tento abordar em todos os primeiros anos o reconhecimento de como a arte pode estar influenciando na sua vida pessoal, ou áreas do mundo do trabalho de forma ampla. (Professor D)

Tem um conhecimento teórico em arte, mas se o aluno experiencia e leva para a vida isso na prática ele vai aprender mais. (Professor B)

Nos discursos dos professores de arte percebemos que a aproximação da arte com a vida do aluno é muito importante para condução das suas aulas. Perceber e considerar isso significa que para eles o ensino não está distante da realidade dos estudantes e nem o conhecimento está "acima" sendo uma verdade imutável como visto no paradigma essencialista (MARQUES, 2000).

Ver o conhecimento como algo construído na partilha, na interlocução é um avanço por considerar a "bagagem" que o aluno acarreta da sua trajetória. Em, outros termos, significa que a educação é entendida pelos professores de arte como mediação da prática social, sendo ela o ponto de partida e chegada de suas práticas educativas. Ainda Brancher e Santos (2019, p. 47) reiteram que "é possível perceber que educar na contemporaneidade exige transformação em nossas práticas, exige do educador olhar para si, (re) significar-se, fazendo com que ele seja/torne-se crítico e reflexivo." Ou seja, o professor na contemporaneidade condiz com um professor reflexivo que através do pensar sobre seu fazer acarreta transformações contínuas em suas práticas.

Segundo Freire (1970) a "educação bancária" trata os conhecimentos como algo a ser depositado no aluno. Esta metodologia de educação foi a dominada nas instituições tradicionais de ensino.

Nela o educador aparece como seu indiscutível agente, como seu real sujeito cuja tarefa indeclinável é "encher" os educandos dos conteúdos de sua narração. Conteúdos que são retalhos da realidade desconectados da totalidade em que se engendram e em cuja visão ganhariam significação. (p.65)

Freire (1970) critica a concepção de educação bancária e fala dos conteúdos como retalhos da realidade que não possuem conexão com a totalidade e nem com a vivência do aluno. Traz o conceito de Palavra mundo para todo o saber 
que o aluno traz de sua família, comunidade e sociedade. Esta Palavra mundo parte da trajetória dos alunos e das suas biografias e percebemos que os professores de arte a valorizam por tentarem dialogar com os conhecimentos da arte e a vida dos estudantes.

Sobre considerar as vivências e as referências dos estudantes, Zabala (1998) também fala desta necessidade de saber o que acontece em aula e "quem são meus alunos?" Pois se os professores se dispõem destes conhecimentos prévios também facilita o seu planejamento, as suas estratégias de ensino e a sua avaliação. Pois reconhecer os saberes dos alunos nesse processo é uma maneira de aproximar o que se ensina de quem aprende.

Deste modo, a ambiência da aprendizagem deve ser levada em consideração também, pois o clima da sala de aula afeta o processo de ensino e aprendizagem. O professor, neste sentido, pode ser o mediador de uma melhor motivação dos alunos sobre as atividades, assim "Os alunos respondem e se adaptam de maneira diversa as propostas educacionais, mostrando maior ou menor interesse e dedicação nas tarefas, em função do que se espera, o que influi a intervenção do professor". (ZABALA, 1998, p. 95)

Em diálogo com esta citação, podemos entender a influência da mediação do professor para se estabelecer um clima de confiança e valorização dos trabalhos dos alunos, pois estão sempre em processo de aprendizagem e precisam que se oferte uma ambiência para atender as expectativas.

Sobre o ambiente na aula de arte, os professores relatam diferentes formas de proporciona-lo. Segue nos discursos a seguir a preocupação com a valorização e exposição dos trabalhos dos alunos, a interatividade e a afetividade na aula de arte:

Sempre termino o semestre com a exposição dos trabalhos dos alunos... Eu sempre digo a eles, não há arte sem público, tudo que a gente produz a gente expõe alguma coisa. Outra coisa que eu faço bastante é sair da sala de aula né não ficar sempre na aula nem que seja no corredor sabe, fazer umas interferências, fazer um recreio estendido coisa que repito bastante é fazer que tudo que eles produzem seja apreciado. (Professor B)

Neste relato do professor B a valorização dos trabalhos de arte dos alunos significa afetividade e motivação e preocupação com o processo criativo. A exposição 
final dos trabalhos dos alunos também intensifica as trocas entre seus colegas, onde ter a visão global de como cada sujeito aprende é importante para a avaliação.

Do mesmo modo os professores de arte demonstram a importância do diálogo:

Dinâmicas de grupo, esta gama metodológica que a gente tenha ela na mão que esteja disponível a dialogar com os estudantes. (Professor $\mathrm{C}$ )

Eu sou uma professora muito afetiva então o afeto com os alunos qualificam minhas aulas porque é através desse afeto que eles querem fazer as atividades. Primeiro que arte é uma disciplina que ela permite desenvolver atividades mais práticas, desenvolver desafios em forma de atividades, pequenas metas e que eles trabalham e eles fazem. Eles têm um espaço com um pouco mais de liberdade em coisas simples em arte como "enquanto você desenha ou escreve um texto sobre o papel da arte na sua vida você pode ouvir música com seu fone, desde que não atrapalhe o colega". Esse tipo de coisa ajuda porque você oferece algo para o aluno que está ali. É então eles terem a possibilidade em sala de aula tendo a responsabilidade de fazer, e confio neles que eles vão fazer. (Professor $E$ )

No trecho do relato "o afeto com os alunos qualifica minhas aulas porque é através desse afeto que eles querem fazer as atividades. (...) e confio neles que eles vão fazer." O docente percebeu durante sua trajetória que o afeto é muito importante para a motivação dos alunos nas atividades para criar com eles um clima de confiança.

Se compararmos com a perspectiva da educação bancária (FREIRE, 1970) o ensino tradicional não tinha esta abertura e afetividade, a postura do professor como único transmissor do saber emitia rigidez e medo com punições possíveis aos alunos que não o obedecessem. Não podemos, neste caso, confundir o clima de afetividade e confiança com permissividade/licenciosidade e falta de autoridade na postura do Professor E em sala de aula. Autoridade docente é diferente de autoritarismo, segundo Freire (1970) a autoridade não é exercer práticas rígidas e autoritárias, mas promover espaços para que os alunos desenvolvam sua autonomia.

Para Candau (2012) a didática deve ter como ponto de partida a multidimensionalidade do processo de ensinar e aprender. Significa apostar na articulação da técnica, do humano e do sócio-político. Estas dimensões dissociadas já foram experiências no ensino do Brasil, segundo a autora, anteriormente, por exemplo, houve o momento em que se priorizou o técnico para silenciar o político. No período da Revolução de 1964, que compreende o período da Ditadura Militar brasileira, tivemos um crescimento industrial, mas o governo reforçava o controle e a repressão. Candau (2012) refere-se a este período como a afirmação do tecnicismo 
na didática. Enfatizava-se a produtividade e a eficiência, e a didática foi uma estratégia ao alcance de pessoas como "produtos" para trabalhar. Esta dimensão tecnicista foi muito presente na educação profissional, pois ela foi alvo da estratégia em formar mão-de-obra para o desenvolvimento econômico. Careceu, neste momento, uma didática de formação com a dimensão humana e sócio-política.

Hoje, a educação profissional no contexto dos Institutos Federais tem como missão a formação integral do estudante, não com o objetivo de "formar mão-de-obra", mas formar sujeitos que compreendam e se relacionem criticamente com o mundo do trabalho. Uma formação para a vida. Neste sentido, o ensino da arte num contexto profissional possui a sua função nas dimensões técnica, humana e sócio-política no processo de ensinar e aprender. No relato dos professores de arte fica claro que suas aulas compreendem esta multidimensionalidade.

Mas eu sempre busco preparar minha aula para que ela tenha um momento de reflexão e um momento de produção. Um momento de reflexão individual e coletiva sobre um assunto e um momento de produção prática visual que pode ser prática coletiva ou individual. Mas tem toda a questão do fazer artístico, questão do espaço que é necessário, a bagunça que se faz. É muito mais fácil trabalhar em grupos do que em individual, porque a arte incita discussão. (Professor B).

O ensino de arte também passou pelo tecnicismo no período da Ditadura Militar. Priorizava-se na arte o fazer, a técnica de pintura, colagem, modelagem, a decoração e cantar músicas prontas. Não se via, por exemplo, a dimensão humana e nem sócio-política no ensino de arte. A arte tem como objetivo o foco na educação além de ensinar simples técnicas. Se olhássemos o ensino de arte pelo viés tecnicista o compreenderíamos como aplicação de práticas prontas, como decoração e enfeite, sem estimular no aluno as tantas outras habilidades e competências que a arte traz. Quando o Professor B diz que sempre prepara sua aula para que tenha também um momento de reflexão e prática porque a arte incita discussão, significa que compreende a multidimensionalidade de ensinar e aprender arte. Nos relatos a seguir podemos perceber esta perspectiva nas suas propostas de ensino.

Do mesmo modo os outros professores colaboram desta perspectiva, pois relatam a importância a prática, da teoria e da reflexão em arte: 


\begin{abstract}
Eu trabalho com projetos educacionais, pedagógicos, usei muito o Fernando Hernandez para pensar essa proposta. Mas eu penso sempre que continuo adepta a concepção de educação do ensino da arte de Ana Mae Barbosa pelo menos quando ela fala em usar os eixos, na proposta triangular. A leitura de imagem, a apreciação a reflexão e a prática com a experimentação, né, a criação. O que faz onde o aluno entenda melhor, pelo menos um pouco mais, eu acho. Mas o que se apresenta na nossa região é de conceitos já fortalecidos de arte. Que vem fortalecido do ensino fundamental. O que eu tenho visto aqui é que os professores dos anos finais geralmente são de outras áreas e infelizmente na disciplina de artes e isso tende a piorar. (Professor D)
\end{abstract}

Tento ler muito a Ana Mae Barbosa, sabe, ela fala, nem tanto no tecnicismo do copiar e colar, nem livre-expressão "vai lá e faz o que quiser". Tem muito isso sabe... "não sei desenhar, meu desenho é feio". Todas estas concepções de feio e bonito muito marcado muito tradicional. Até digo que o desenho feio está na moda. "Mas está bonito, olha para o expressionismo alemão", eu disse... Não existe mais isso, pessoal, feio e bonito. Quando comecei Mitologia Grega gostaram do tema como mito do cavalo alado. Eles são apaixonados por cavalos. Aí fizemos os cavalos com asas, fizemos o cenário do nascimento do Pegasus e a morte. Daí eles viram um anime, sabe? Já se animaram! Tento fazer assim, quando eu cheguei aqui eu era nova na cidade, fiz uma aula sobre arte e cultura da cidade. Peguei eventos, campeiradas. Quem são os artistas da cidade? Quais monumentos que tem? (...) Aí em seguida nós olhamos o brasão, analisamos o brasão da cidade deles e o de Lisboa. Para eles verem que estão num mundo, não numa redoma, mas estão dentro do mundo. (Professor A)

Destaca-se nos discursos dos professores A e D a parte em que ambos referem-se a "conceitos e concepções" fortalecidos e formados em arte, como por exemplo, o "feio e o bonito". Para as professoras de arte fica claro que possuem em seu trabalho a preocupação de desconstruir estas concepções ultrapassadas: "Mas está bonito, olha para o expressionismo alemão", disse a professora ao aluno. Pois em arte, principalmente se pensarmos em termos de relativismo cultural, diferentes culturas possuem seus conceitos do que é belo, do que é feio. Não há uma beleza universal em arte que encaixe tudo no mesmo padrão. Muito desta padronização de beleza vem do histórico tecnicista no ensino de arte, onde não se envolviam gostos, criatividade e não se pensavam em diferenças culturais.

Ainda sobre a multidimensionalidade do processo de aprender e ensinar, as professoras fazem referência, nos seus relatos, à abordagem triangular de Ana Mae Barbosa no ensino de arte. Esta abordagem possui a ênfase na construção do conhecimento em arte, a pesquisadora brasileira Ana Mae Barbosa partiu deste objetivo para pensar a abordagem que envolve: a criação, a apreciação interpretativa e a contextualização histórica, social e antropológica e/ou estética 
da obra (BARBOSA, 2007). Este é o tripé que embasa o ensino da arte a partir da abordagem triangular. Não se trata de um método fechado, mas algo que o professor vai adaptá-lo conforme sua realidade. Esta proposta traz a ligação entre teoria e prática em arte, pois anteriormente com o "simples fazer" a prática em arte não partia de uma reflexão, de uma interpretação como algo acoplado com a teoria. A compreensão sobre a arte na sociedade, na cultura, sobre as imagens da cultura visual participam hoje do ensino de arte, mas não de uma maneira decorativa nem tecnicista, mas como parte da nossa formação humana, estética, social e política.

Como o contexto da educação profissional que estão inseridos estes professores de arte, é o do Ensino Médio Integrado, pressupõe-se que todos os componentes curriculares possuem sua importância para a vida do estudante. Além do mais, a integração é o objetivo de uma formação inteira, onde não se separa o trabalho manual do trabalho intelectual. A arte, neste contexto, ocupa a dimensão estética, perceptiva, criativa, sensível, onde é possível aprender através da arte e aprender através da experiência estética. No relato dos colaboradores eles demonstram como a arte tem contribuído para a integração com outros componentes curriculares.

\begin{abstract}
A ação mais forte que nós temos no campus é a PPI, que é maior proposta integradora, então sempre procuro inserir a arte na PPI. Que geralmente é um tema voltado ao curso técnico, mas eu procuro inserir a arte sem deixar de trabalhar arte. E nesse sentido depois estamos engatinhando nesse sentido de tentar reunir mais as disciplinas, no inicio eu entendia que era mais possível, porque os professores não tinham tantas horas em sala de aula. Mas a gente não consegue sentar e planejar coletivamente, né entre ações mais articuladas entre mais disciplinas, mas a gente tenta. Temos feito alguns trabalhos bem interessantes, voltados a português e literatura, e agora temos feito uma tentativa bem interessante com física e educação física. Acho que são esses lugares, no meu ponto de vista poderia ser mais. (Professor D)
\end{abstract}

Neste relato percebe-se a ação integradora com outros componentes do currículo como português e literatura na área das Linguagens e também com física e educação física. O conhecimento na perspectiva integradora não é fragmentado, pois quando pressupõe a complexidade da realidade é possível ver a necessidade de entendê-la de modo global. Hoje, a educação profissional prepara para a vida e o mundo do trabalho, então o conhecimento em arte e em outras áreas do saber não 
são "aplicáveis" no trabalho, e sim dialogam entre si e conformam a formação do sujeito para a autonomia.

O professor $C$ também relata dialogar com outras disciplinas em sua instituição de ensino:

\begin{abstract}
Bom, a gente tem alguns projetos assim que integram com outras disciplinas, sempre tenho afinidade com as professoras de português, sempre tivemos um projeto que integrava literatura e arte. Então a gente trabalhou com temáticas voltadas a poetas e estamos no trabalho coletivo que foi desenvolvido ao longo do ano. Este espaço de projetos é restrito porque os alunos tem uma carga horaria de 16 e 17 disciplinas na semana. A gente tenta integrar na própria disciplina, por fora da aula participa mais quem quer, mas temos uma participação significativa, interessante assim o quantitativo de alunos e como que é a participação da arte neste contexto. Ano passado tivemos um trabalho voltado pra literatura e estética e foi bastante interessante. Temos projetos de cura duração, longa duração. Tenho projeto com outro professor que funciona fora do horário que é da parte musical, mas não é obrigatório. (Professor $\mathrm{C}$ )
\end{abstract}

Neste relato a arte integra-se mais facilmente com a Literatura em função da linguagem e da estética. Mas na narrativa do Professor A enfatiza a importância de dialogar com a arte e outros componentes sem vê-la como algo acessório de outras disciplinas:

É que como a arte é interdisciplinar ela passa por qualquer uma das disciplinas, por exemplo, com o professor de biologia fazer as células, mas tenho medo de ficar como se fosse o acessório da outra disciplina, tem que ser um jeito que as duas conversem. Por exemplo, todos eles gostam de desenhar cavalo, mesmo que eu não dê a proposta até o autorretrato eles fazem com cavalo. Aí a professora na aula de Zootecnia vai ver a parte externa da anatomia dos bichos, aí daqui a três semanas vamos fazer isso aí. Eu disse quem sabe eu vou contigo lá para baixo, né, aí eles podem ir com caderno e fazer as qualidades, e desenhar, um cavalo tem um nariz mais comprido o outro não. Agora mesmo eles vão fazer o desenho das raças, das ovelhas, articular com a Zootecnia. Com a professora da Agricultura a gente pode mostrar pra eles aqueles ilustradores antigos que vinham para o Brasil, olha como não existia fotografia, faziam o desenho, aí expõe. Aqui tem muita coisa bonita, sair por aí pra fazer os desenhos das plantas. (Professor A)

A relação entre o Curso Técnico Integrado Zootecnia possui disciplinas como Agricultura e o professor de arte relaciona o estudo da paisagem com ilustradores e pintores que vinham ao Brasil para documentar a fauna e a flora do país. Assim é possível levar os alunos o conhecimento de história e os fatos de outras 
épocas e desenvolver neles habilidades e competência para a apreciação e o senso estético.

O professor E destaca a importância da integração e também relata que trabalha muito com a dimensão estética que favorece a aprendizagem dos alunos:

\begin{abstract}
Acho que integração é importante... É importante a pedagogia através do trabalho, trabalhando nas coisas, na pesquisa, em práticas artísticas... Nós trabalhamos com projeto na sala de aula, determinamos um projeto. Na PPI que vou trabalhar com a estética e com uso claro de informações, como teoria da cor, a simetria. Com especificamente artísticos, temos um projeto com a professora de português que vem funcionando a partir do teatro e com projetos extra classe, temos atividades de literatura, cinema e atividades ligadas aos núcleos inclusivos do IF, então parte disso é exibição de filme. Temos projeto de extensão que é contar de história, alguns alunos contam histórias através de interpretação teatral, criação de instrumentos, reaproveitamento de materiais visando à sustentabilidade do campus. (Professor E)
\end{abstract}

Nesta mesma perspectiva o Professor B também relaciona a importância do estudo da semiótica para o ensino de arte no currículo integrado:

Temos as práticas profissionais integradas, a PPI. Geralmente a arte tem cumprido parte nisso, sempre participo geralmente com esta parte da semiótica, criar logotipo, sempre esta presente, a arte criar entra como os elementos básicos da comunicação visual. (Professor B)

Percebemos no relato dos professores o modo como cada um na sua instituição de ensino trabalha a arte e sua integração. A maioria dos professores demonstra um maior diálogo da arte com as linguagens como português e literatura, pois há mais aproximação teórica entre elas. Sinalizaram também a Prática Profissional Integrada que é um projeto articulador nos cursos técnicos integrados com os componentes curriculares. Em comum, alguns professores trouxeram a cargahorária alta dos alunos e professores em sala de aula, o que dificulta para que o coletivo se organize e pense mais sobre a integração.

Parsons (2010) enfatiza o desafio de trabalhar o currículo integrado, pois significa que o professor e os estudantes precisam pensar em um tema ou problema que pode envolver Sociologia, Ciências, Matemática etc., e pensar também no conteúdo que é especifico da aula de arte. Assim exemplifica:

Por exemplo, se o tópico a ser estudado é o lixo da comunidade local - o que é, de onde vem e para onde vai e o que ele informa sobre a comunidade - os elementos substantivos consistem no caráter biológico ou químico, ou 
econômico, ou social, ou político e nas origens do lixo. Os elementos artísticos consistem em achar maneiras de representar a compreensão que os estudantes desenvolvem do assunto e suas atitudes em relação ao lixo. Esta última pode requerer olhar para os trabalhos de outros artistas a respeito do lixo e talvez requeira a prática de relevantes habilidades e técnicas; mas essas não devem ser isoladas do pensamento sobre o lixo. (PARSONS, 2010, p. 310)

Esta exemplificação de Parsons (2010) sobre a integração de componentes curriculares para a compreensão a partir de um fenômeno local, como o lixo, demonstra que o conhecimento e o saber não são estanques, pois a realidade em que vivemos é complexa. A arte neste sentido aproxima-se para envolver questões que façam sentido à vida dos estudantes e a vida comum numa democracia.

Enfim, a partir da narrativa dos professores de arte colaboradores sobre suas práticas educativas, concluímos que o ensino de arte não serve para decorar e enfeitar, quando tratado na multidimensionalidade do processo de ensinar e aprender (CANDAU, 2012). Significa que quando articulam a técnica, o humano e o sóciopolítico, a práxis docente fica voltada para a transformação da realidade através do ensino de arte.

Para Ciavatta (2005) o ensino médio integrado ao ensino técnico significa preparar para o mundo do trabalho através de uma formação integrada. A formação integral sugere tornar integro e inteiro o ser humano que é desconexo historicamente pela divisão social do trabalho entre quem faz e quem pensa, significa:

Como formação humana, o que se busca é garantir ao adolescente, ao jovem e ao adulto trabalhador o direito a uma formação completa para a leitura do mundo e para a atuação como cidadão pertencente a um país, integrado dignamente à sua sociedade política. Formação que, neste sentido, supõe a compreensão das relações sociais subjacentes a todos os fenômenos. (CIAVATTA, 2005, p.3)

Neste contexto discorrido por Ciavatta (2005) os Institutos Federais trazem a integração como forma e direito a uma formação integral, onde a leitura e a compreensão do mundo sejam crítica e política. A arte possui uma dimensão importantíssima para esta formação. A partir das narrativas dos professores de arte colaboradores sobre suas práticas educativas, apesar de todos os desafios em relação ao ensino de arte na educação profissional, estes professores resistem e provocam a pensar no potencial da arte como experiência criadora e emancipadora. 


\section{Considerações Finais}

Considerando o contexto do currículo integrado na educação básica profissional e tecnológica os professores de arte demonstraram, em suas narrativas, trabalhar na perspectiva da multidimensionalidade do ensino, segundo Candau (2012) fala a dimensão técnica, humana e política sempre articuladas.

A partir disso, foram destacadas a importância em relacionar os conteúdos de arte com a vida do estudante, o que dá uma dimensão de interlocução entre os saberes e não uma mera transmissão do conhecimento. Deste modo a aprendizagem é construída na relação entre as experiências de vida e os conteúdos acadêmicos.

Os professores destacaram a importância da ambiência na sala de aula para favorecer a aprendizagem dos alunos, o clima de confiança e diálogo que não significa permissividade. Deste modo, os professores enfatizam em suas estratégias de ensino e metodologia a prática, a reflexão e a contextualização no ensino de arte, partindo da proposta Triangular de Ana Mae Barbosa.

Assim, no contexto do currículo integrado, hoje, na educação profissional não é mais para aplicar técnicas e métodos nas indústrias e mercados de trabalho, mas sim parte-se da dimensão humana, estética e ética. A arte na educação profissional contribui para a formação de modo global onde a criatividade, a sensibilidade, a percepção são importantes em todas as dimensões da vida.

\section{Referências}

ANTUNES, Ricardo; ALVES, Giovanni. As mutações do mundo do trabalho na era da mundialização do capital. Educação e Sociedade, v. 35, n. 87, p. 335-351, 2004.

ARAUJO, Ronaldo; FRIGOTTO, Gaudêncio. Práticas Pedagógicas e Ensino integrado. Revista Educação em Questão, Natal, v. 52, n. 38, p. 61-80, 2015.

ARAÚJO, Ronaldo; RODRIGUES, Doriedson. Referências sobre práticas formativas em educação profissional: o velho travestido de novo frente ao efetivamente novo. Revista Educação Profissional, v. 36, n.2, 2010.

BARBOSA, Ana Mae. Inquietações e mudanças no ensino da arte. São Paulo: Cortez, 2007.

BARBOSA, Ana Mae. Arte/educação contemporânea: Consonâncias internacionais. 3a Edição. São Paulo: Cortez, 2010. 
BARDIN, Laurence. A Análise de Conteúdo. São Paulo: Edições 70, 2016. BRANCHER, Vantoir; SANTOS, Juliani. Desassossegos: Os Trajetos formativos que tecem as concepções de formação de professores na EBPTT. Revista Educação e Linguagem, v. 6, n. 2, p. 44-57, 2019.

BRASIL. Lei $n^{\circ} 11.892$, de 29 de dezembro de 2008. Institui a Rede Federal de Educação Profissional, Científica e Tecnológica, cria os Institutos Federais de Educação, Ciência e Tecnologia e dá outras providências. Diário Oficial da União, Brasília, 30 dez. 2008.

CANDAU, Vera. Didática em questão. Petrópolis, Editora Vozes, 2012.

CIAVATTA, Maria. A formação integrada: a escola e o trabalho como lugares de memória e identidade. Revista Trabalho Necessário, v.3, n.3, p.1-20, 2005.

COELHO, Consolação; SOUSA, Antonia. A reforma do Ensino Médio: Ameaças às concepções de formação integrada. Revista Labor, v. 2, n. 21, p. 11-23, 2019.

FREIRE, Paulo. Pedagogia do Oprimido. Rio de Janeiro: Paz e Terra, 1970.

HERNÁNDEZ, Fernando. Transgressão e mudança na educação: Os projetos de Trabalho. Porto Alegre: Artmed, 1998.

MARQUES, Mario. A Educação no limiar do terceiro milênio: exigente de outro paradigma. Revista Contexto e Educação. v. 15, n.59, p. 113-128, 2000.

MARX, Karl. Manuscritos econômico-filosóficos. Tradução de Jesus Ranieri. São Paulo: Boitempo, 2004.

MOURA, Dante Henrique. A formação de docentes para a educação profissional e tecnológica. Revista Brasileira da Educação Profissional e Tecnológica, v. 1, n. 1, p. 23-37, 2008.

PARSONS, Michael. Curriculum, Arte e cognição integrados. In: BARBOSA, Ana. Arte/educação contemporânea: Consonâncias internacionais. $3^{a}$ Edição. São Paulo: Cortez, 2010. (p. 295-318)

SAVIANI, Demerval. Trabalho e educação: fundamentos ontológicos e históricos. Revista Brasileira de Educação, v.12, n. 34, p. 152-165, 2007.

TRIVIÑUS, Augusto. Introdução à pesquisa em Ciências Sociais. São Paulo: Atlas, 1987.

ZABALA, Antoni. A prática Educativa: Como ensinar. Ed. Artmed, Porto Alegre, 1998. 


\section{Luana Cassol Bortolin}

Farroupilha, RS, Brasil.

Atualmente é da Universidade Federal do Pampa, Revisor de periódico da Revista Labor, Coordenadora de formação continuada de Arte da Prefeitura Municipal de Uruguaiana e Professora de arte da Secretaria Municipal de Educação Uruguaiana.

Email: luana.cassol@hotmail.com

Link do Lattes: http://lattes.cnpq.br/3812280266713021

\section{Vantoir Roberto Brancher}

Santa Maria, RS, Brasil

Doutorado em Educação (2013) pela Universidade Federal de Santa Maria - UFSM, realizou o Doutorado Sanduíche no Instituto de Educação da Universidade de Lisboa (2011). É professor efetivo do Instituto Federal de Educação Ciência e Tecnologia Farroupilha, atuando em cursos de Licenciatura e PósGraduação.

Email: vantoir.brancher@iffarroupilha.edu.br

Link do Lattes: http://lattes.cnpq.br/3260077562370842

\section{Catiane Mazzoco Paniz}

Farroupilha, RS, Brasil

Doutorado em Educação em Ciências pela Universidade Federal de Santa Maria (2017). É professora de ensino básico, técnico e tecnológico do Instituto Federal Farroupilha- campus São Vicente do Sul.

Email: catiane.paniz@iffarroupilha.edu.br

Link do Lattes: http://lattes.cnpq.br/7119419910632854

Recebimento: 25/05/2020

Aprovação: 12/08/2020

\section{Q.Code}


Revista Labor

Programa de Pós-graduação em Educação, Universidade Federal do Ceará

Fortaleza-CE-Brasil

\section{Editores-Responsáveis}

Prof. Dr. Enéas de Araújo Arrais Neto, Universidade Federal do Ceará - UFC, Brasil

Prof. Dr. Arno Münster, Universidade de Amiens - Paris, França 